\title{
Enfermagem como opção: perfil de graduandos de duas instituições de ensino
}

\author{
Nursing as an option: profile of undergraduate of two teaching institutions
}

Enfermería cómo opción: perfil de graduandos de dos instituciones de enseñanza

\section{Thelma Spíndola', Elizabeth Rose da Costa Martins', Márcio Tadeu Ribeiro Francisco"I}

'Universidade do Rio de laneiro. Rio de Janeiro, RJ

"Universidade Veiga de Almeida. Rio de laneiro, RJ

Submissão: 29/11/2006

Aprovação: 02/03/2007

\section{RESUMO}

Estudo descritivo-exploratório, com objetivo de comparar o perfil sócio-econômico e fatores Que interferem na opção pela enfermagem dos alunos de duas instituições de ensino no município do Rio de Janeiro. Participaram 152 alunos da instituição (A) e 120 da (B) Que ingressaram na graduação em 2004 e 2005. A análise evidenciou Que em sua maioria são adultos jovens, mulheres, solteiras, pertencem às classes B e C. O mercado de trabalho em expansão e a oportunidade de uma remuneração melhor são fatores Que atraem o alunado da faculdade particular para enfermagem. A divulgação da profissão junto à sociedade e, especialmente, entre os alunos Que buscam uma opção profissional torna-se relevante, considerando a desinformação daQueles Que ingressam na graduação em enfermagem. Descritores: Educação em enfermagem; Enfermagem; Estudantes de enfermagem; Ensino Superior.

\section{ABSTRACT}

This is a descriptive-exploratory study, aiming at comparing socioeconomic profile of students of two teaching institutions of the municipality of Rio de Janeiro and factors that interfere in their option to choose Nursing. The study was composed by 152 students of Institution (A) and 120 of (B) who were admitted to the undergraduate course in 2004 and 2005 . The analysis evidenced that the majority belongs to middle and lower middle class and are young adults, single women. An expanding labor market and an opportunity of a better salary are the main factors that attract students of private schools to nursing career. It is important to the profession to be known in society and, especially, among students who search for a professional option, considering the lack of information of students who are admitted to the Nursing undergraduate course.

Descriptors: Education, nursing; Nursing; Nursing students; Higher Education.

\section{RESUMEN}

Estudio descriptivo exploratorio Que tiene como objetivo comparar el perfil socioeconómico de alumnos de dos instituciones de enseñanza del municipio de Rio de Janeiro y los factores Que interfieren en la opción por Enfermería. Participaron 152 alumnos de la institución (A) y 120 de la (B) Que ingresaron en la carrera de Enfermería en 2004 y 2005 . El análisis evidenció Que en su mayoría pertenecen a la clase media y media baja y son mujeres jóvenes y solteras. El mercado laboral en expansión y la oportunidad de una mejor remuneración son los factores Que atraen los alumnos de la Facultad privada para la carrera de Enfermería. La divulgación de la profesión junto a la sociedad y, especialmente, entre los alumnos que buscan una opción profesional se torna relevante, considerando la desinformación de Quienes ingresan en la Facultad de Enfermería.

Descriptores: Educación en Enfermería; Enfermería; Estudiantes de Enfermería; Enseñanza Superior. 


\section{INTRODUÇÃO}

Na eualidade de docentes da Faculdade de Enfermagem da Universidade do Estado do Rio de Janeiro e convivendo com alunos Que ingressam no $1^{\circ}$ período de graduação temos percebido Que o aluno Que busca a enfermagem tem características peculiares, dentre elas a afinidade pela área da saúde. Em muitas situações o curso de enfermagem não foi a primeira opção na escolha do Vestibular persistindo, ainda nos dias atuais, a crença de Que estando inseridos numa carreira da área de saúde poderão com maior facilidade fazer a transposição para outra de seu interesse.

Em estudo(l) foi evidenciado Que a escolha da profissão pelos alunos Que realizam vestibular para Enfermagem baseia-se, principalmente, na inclinação para a área da saúde, como, também pela proporção candidato/ vaga ser bem menor do que nos cursos considerados de maior prestígio social.

Acreditam Que o próprio sistema de seleção à universidade ainda reproduz as diferenças existentes entre as classes sociais "determinando Que nas carreiras de menor "status" social, predominem alunos procedentes das classes de menor poder econômico (e cultural )"(1).

Visando divulgar mais a profissão de enfermagem, em 1999. tivemos a iniciativa de cadastrar na Sub-reitoria de Extensão da Universidade do Estado do Rio de Janeiro o Projeto de Extensão "Afinal, o Que é ser Enfermeiro? Falando de nós para vocês". Neste projeto são realizadas ações educativas com alunos do Ensino Médio, de escolas públicas (sendo também oferecido para as escolas privadas), do município do Rio de Janeiro. Através de palestras ilustradas com recursos audiovisuais e estratégias de sensibilização os alunos são esclarecidos em relação à profissão, ressaltando-se as atribuições do Enfermeiro e demais profissionais da equipe de enfermagem, o mercado de trabalho e áreas de atuação.

Nestes contatos com os alunos de ensino médio percebemos Que a enfermagem, ainda hoje, é uma profissão pouco conhecida, não sendo visualizada a dimensão de suas ações junto à clientela Que assiste e, tão pouco, Que se trata de um curso de nível superior. Estas constatações tornam evidente a falta de divulgação desta profissão para a população em geral e, especialmente, entre os alunos do ensino médio, muitas vezes indefinidos em relação a uma opção profissional.

Vale acrescentar Que, em muitas situações, os jovens acabam sendo absorvidos, precocemente, pelo mercado de trabalho em função da necessidade familiar de um retorno financeiro mais imediato. Nem sempre permanecem na escola por um período superior a oito anos de estudo, ou seja, geralmente só cursam até o ensino fundamental.

De acordo com dados do censo demográfico, do Instituto Brasileiro de Geografia e Estatística ${ }^{(2)}$, no ano de 2000 do total da população brasileira Que freqüentava creche ou escola, havia no ensino fundamental cerca de 33.886.031; no ensino médio 8.302.599; no pré-vestibular 440.046; no ensino superior 2.864 .046 na graduação e 162.512 nos cursos de pós-graduação em nível de mestrado e doutorado. Nota-se que ocorre um afunilamento gradativo entre os diversos níveis de ensino, com uma maior concentração de estudantes no ensino fundamental, diminuindo progressivamente até chegar ao ensino superior.

De acordo com a Pesquisa Nacional por Amostra de Domicílios ${ }^{(3)}$, em 2003 a população brasileira com 25 anos ou mais de idade, cerca de 92.810 .518 pessoas, apenas $11,6 \%$ tinham 12 ou mais anos de estudo. Entre as regiões do Brasil com maior concentração desta população destacam-se as regiões sudeste $(14,1 \%)$ e sul $(12,9 \%)$, respectivamente.

O mercado de trabalho brasileiro desde os anos 90 tem sofrido alterações, sendo reduzido o número de trabalhadores na indústria de transformação e se expandiu nos setores de prestação de serviços e comércio. O avanço da tecnologia com a substituição do homem pela máeuina é um dos principais motivos da eliminação de postos de trabalho na indústria. O rendimento médio da população ocupada no mês de março de 2005 foi de R\$945,20. Na área de educação, saúde, serviços sociais, administração pública, defesa e seguridade social, este rendimento médio foi da ordem de $\mathrm{R} \$ 1.329,10$, sendo uma das áreas melhor remuneradas ${ }^{(4)}$. Estes achados talvez justifieuem a procura de muitas pessoas por estas áreas e, dentre elas, a da saúde.

Por outro lado determinadas profissões, como a enfermagem, em função das categorias profissionais Que abrange possibilitam a absorção da mão de obra daqueles Que possuem o ensino fundamental e/ou médio desde Que realizem um curso profissionalizante, como o auxiliar de enfermagem (ensino fundamental), o técnico de enfermagem (ensino médio). Para ser enfermeiro é necessário ter o curso superior.

Segundo dados do Conselho Federal de Enfermagem ${ }^{(5)}$ até dezembro de 2004 tinha-se o registro de 179.739 enfermeiros (10,9\%), 661.080 técnicos de enfermagem $(40,2 \%)$ e 802.788 auxiliares de enfermagem $(48,8 \%)$ para todo o território nacional. Deste total, no estado do Rio de Janeiro existiam 16.695 enfermeiros, 40.257 técnicos e 114.471 auxiliares de enfermagem. Como podemos observar o Quantitativo de enfermeiros ainda é bastante reduzido, se considerarmos a expansão territorial e a necessidade deste profissional em nosso país.

No convívio com os graduandos temos observado que ao optar pela enfermagem os alunos, em sua maioria, estão buscando uma carreira da área de saúde e a absorção pelo mercado de trabalho. Em algumas situações, ao cursarem a enfermagem nem sempre recebem o apoio dos familiares em função do pouco prestígio social da profissão se comparada a outras carreiras da área de saúde.

Estudando a temática ${ }^{(6)}$, numa peseuisa realizada com alunos da Faculdade de Enfermagem da UERJ, foi constatado Que estes ao buscarem a profissão tinham aptidão pela área da saúde e interesse em ajudar o próximo. Alguns afirmaram Que fizeram esta opção porQue a enfermagem era próxima da medicina e demais carreiras da área de saúde, apresenta um fértil mercado de trabalho e está relacionada ao cuidado e prevenção de doenças. Ressaltaram, todavia, Que os profissionais Que atuam na área podem ser úteis ao próximo, solidários e educadores disseminando o cuidado com a saúde das pessoas.

A relação candidato/vaga no Vestibular para o curso de enfermagem tem sido modificada. No último concurso (2005), esta proporção foi de 7,9 candidatos por vaga na Universidade Federal do Rio de Janeiro (UFRI) ${ }^{(7)}$ onde são oferecidas 144 vagas, 1 3,3 na Universidade Federal Fluminense (UFF) ${ }^{(8)}$ para 100 vagas e 8,8 na Universidade do Estado do Rio de Janeiro (UERJ) ${ }^{(9)}$ com 80 vagas. Podemos observar, a partir destes resultados, Que a área de enfermagem tem sido uma opção para àQueles interessados no 
acesso ao ensino superior, em muitas situações, ansiosos por melhores oportunidades de trabalho.

Em seus estudos ${ }^{(10)}$ com alunos ingressantes na enfermagem revelam que estes se sentem realizados por passar no vestibular e valorizados por estar em uma Universidade, todavia, têm incertezas Quanto ao curso e futuro por enfrentarem uma nova situação.

$O$ perfil do aluno ingressante na enfermagem tem motivado autores $^{(11,12)}$ a estudar a temática, sendo descrito como de jovens com idade entre 18 e 22 anos, predominantemente, do sexo feminino Que dependiam economicamente dos pais ${ }^{(1)}$. Em outro estudo $^{(12)}$ foi verificado Que os alunos eram em sua maioria jovens do sexo feminino, casadas e sem filhos, Que trabalhavam, porém a minoria atuava na área da saúde.

Vale acrescentar Que na FENF/UERJ outros professores têm estudado e discutido esta temática Que apresenta diferentes matizes, tal seja os conflitos do estudante de enfermagem na construção da imagem da profissão analisado em $1997^{(13)}$. Em 2000 a autora ${ }^{(14)} \mathrm{em}$ sua Tese analisou o imaginário dos familiares de alunos ingressantes na faculdade de enfermagem, denotando a preocupação com os pais apoiando ou não os filhos na escolha por uma profissão. A autora visualiza a profissão com forte sentido humanitário e reconhece a importância da enfermagem mediante o conhecimento adQuirido e aplicado na prática profissional.

Assim, optar pela enfermagem ao realizar o Vestibular para ingresso no curso superior, pode traduzir o simples desejo de acesso a uma profissão da área da saúde como, também, o conhecimento prévio e uma escolha consciente. Entretanto, o perfil deste aluno, suas fontes de informação, áreas de interesse e os fatores Que influenciam nesta opção são os focos desta investigação.

Diante do exposto este estudo tem como objetivos:

a) Identificar o perfil sócio-econômico dos alunos do $I^{\circ}$ período de graduação em enfermagem.

b) Verificar os fatores Que influenciam na opção pela enfermagem.

\section{METODOLOGIA}

Trata-se de um estudo descritivo-exploratório em função do objeto de estudo selecionado para investigação - os alunos ingressantes na enfermagem. O estudo descritivo-exploratório possibilita um melhor entendimento do processo de investigação e descreve os fenômenos de determinada realidade ${ }^{(15)}$. A natureza descritiva favorece a obtenção de dados necessários para o desenvolvimento de uma pesQuisa e, através da descrição dos fatos podemos interpretar a realidade analisando os acontecimentos.

A pesquisa Quantitativa envolve a coleta sistemática de informação numérica, normalmente mediante condições de muito controle, além da análise dessa informação, utilizando procedimentos estatísticos ${ }^{(16)}$. Esta modalidade pesquisa, é utilizada Quando a situação exige um estudo exploratório para um conhecimento mais aprofundado do problema ou objeto de estudo ou Quando se necessita de um diagnóstico inicial da situação ${ }^{(17)}$.

Foi realizada em duas instituições de ensino superior, uma pública (A) e outra privada (B), localizadas no município do Rio de Janeiro Que oferecem o curso de graduação em enfermagem. Fizeram parte do estudo os alunos Que ingressaram no Vestibular de 2004 e 2005 do primeiro e segundo semestres, respectivamente, perfazendo um total de 152 alunos da instituição pública (ingressam em média cerca de 40 alunos a cada semestre) e 120 alunos da instituição privada (ingressam em média 25/30 alunos a cada semestre por turno).

Para compor o estudo foram selecionadas variáveis sócioeconômicas (sexo, idade, renda familiar e outras) e àQuelas relacionadas com a problemática, como: informações a respeito da profissão; presença de familiares Que trabalham na área de saúde; realização de outros Vestibulares, dentre outras).

Como instrumento de coleta de dados foi aplicado um Questionário composto de 25 Questões sendo 23 fechadas e 02 abertas na instituição privada e outro semelhante com 27 Questões sendo 25 fechadas e 02 abertas na instituição pública. Antes de ter início esta investigação este Projeto foi apreciado pelo Comitê de Ética em Pesquisa do Hospital Universitário Pedro Ernesto (HUPE), seguindo a resolução 196/96 ${ }^{(18)}$. De posse da referida autorização para a sua execução procedemos às etapas seguintes.

Para aplicação do instrumento a Direção das duas Instituições de Ensino envolvidas na pesquisa tomaram ciência dos objetivos do estudo e solicitou-se autorização para aproximação aos alunos regularmente matriculados no primeiro período de graduação.

Para aplicação do Questionário foram ineuiridos os alunos do Vestibular de 2004 e os regularmente matriculados no primeiro período de graduação em enfermagem do ano de 2005, explicamos os objetivos do estudo e solicitamos a participação voluntária no mesmo. Aos interessados entregamos o Termo de Consentimento Livre e Esclarecido, onde tomaram ciência do conteúdo do estudo e autorizaram as pesquisadoras a utilizarem os resultados, juntamente com o Questionário. Recolhemos os mesmos ao final do dia (manhã ou tarde).

Os dados foram coletados no período de março a agosto de 2005, sendo tabulados e analisados aplicando-se a estatística descritiva conforme os autores ${ }^{(19)}$ preconizam, tendo-se evidenciado os resultados em freeüências absoluta e percentual representados em tabelas e gráficos ${ }^{(20)}$.

\section{RESULTADOS E DISCUSSÃO}

A distribuição dos discentes conforme o sexo evidenciou Que em ambas as instituições a maioria dos jovens são do sexo feminino sendo $85,5 \%$, na (A) e $89,1 \%$ na (B). Este resultado está em consonância com demais estudos ${ }^{(11,12)}$ realizados sobre a temática Que evidenciam a predominância de mulheres na graduação em enfermagem.

Em relação à faixa etária do conjunto amostral ficou evidenciado Que 48\% das jovens da instituição (A) têm idades entre 17-19 anos, seguidos de $36 \%$ com jovens na faixa de 20-22 anos; enquanto Que na (B) 40\% têm 25 anos ou mais, seguidos de 23,3\% com idades entre 20-22 anos. Este resultado evidencia Que o grupo investigado é composto por adultos jovens, estando em consonância com a literatura estudada ${ }^{(3,11,12)}$. Outro aspecto Que pode ser observado é Que na instituição (B) ocorre uma prevalência de jovens com idade superior aos da faculdade (A).

Quanto ao estado civil em ambas as instituições ocorre uma prevalência de solteiros sendo 95\% na faculdade (A) e 73,3\% na faculdade (B). Estes resultados estão em consonância com a literatura $^{(11,12)}$ e refletem a realidade da população brasileira onde as mulheres têm optado em casar-se mais tarde priorizando a 
formação profissional e sua inserção no mercado de trabalho.

Em relação à existência de filhos a maioria dos jovens em ambas as instituições não possui, com 97\% na instituição (A) e 79, 1 \% na (B). Este resultado pode ser correlacionado com o estado civil das jovens e a priorização da formação profissional/inserção no mercado de trabalho, sendo penoso para a mulher Que possui filhos conciliar as atividades acadêmicas e a vida privada.

A maioria dos jovens em ambas as instituições residem com familiares sendo $94,7 \%$ na faculdade (A) e $83,3 \%$ na (B) e residem na região norte do município (40\%) ou fora do município (30\%) na (A). Na instituição (B) 47,5\% residem na região norte, 15,8\% no centro e $15 \%$ na região oeste do município. Estes resultados evidenciam Que em sua maioria os alunos residem próximos às instituições de ensino Que se localizam na região norte do município.

Quanto ao tipo de moradia dos discentes das duas instituições a maioria reside em moradia própria (82\% na (A) e 66,6\% na (B)), tendo 3-4 habitantes por casa (61\% na (A) e $65 \%$ na (B)).

Em relação à renda familiar dos discentes foi evidenciado Que na instituição (A) 37\% têm renda superior a 05 salários mínimos (na ocasião da coleta equivalente a $\mathrm{R} \$ 300,00$ ) e 22,4\% de 3-4 salários; na instituição (B) 40,8\% superior a 05 salários e $21,6 \%$ de 4-5 salários. Estes resultados se comparados com os dados relativos ao tipo de moradia e região do município em Que os discentes residem se complementam. Por outro lado, vale considerar Que sendo a instituição (B) particular faz-se necessário Que o aluno tenha rendimentos ou Que seus familiares disponibilizem para freqüentar seus cursos.

Quanto ao trabalho remunerado os dados indicam Que $92 \%$ dos alunos da instituição (A) não realizam atividade remunerada, eneuanto Que $62,5 \%$ dos alunos da instituição (B) realizam atividade remunerada. Este resultado pode ter relação com o tipo de instituição pública (A) e privada (B), bem como com o horário em Que os cursos são oferecidos. Na faculdade pública o horário é integral, na particular é parcial (manhã, tarde ou noite) o Que possibilita ao aluno estar inserido no mercado de trabalho. Quanto ao tipo de atividade realizada pelos alunos que trabalham na faculdade (B) 61,3\% são profissionais da área de saúde (nível médio).

Quanto à origem da instituição onde os alunos cursaram o ensino médio $53,9 \%$ da faculdade (A) estudaram em escolas particulares seguidos de $46 \%$ Que são oriundos de escolas públicas. Fizeram curso pré-vestibular (85\%) do total de alunos. Na faculdade (B) $62 \%$ são oriundos de escolas particulares, seguidos de $37,5 \%$ de escolas públicas e $(77,5 \%)$ do total de alunos não fez curso pré-vestibular.

Os dados refletem a dificuldade de o aluno da escola pública ser aprovado no vestibular e a necessidade da realização de um curso pré-vestibular. Para minimizar esta desigualdade social o Ministério da Educação propôs à adoção do sistema de cotas, Que reserva um percentual de vagas para alunos oriundos de escolas públicas. A Universidade Nacional de Brasília (UNB) e a Universidade do Estado do Rio de laneiro (UERJ), a partir de 2004 adotaram este sistema. As universidades federais têm discutido o tema e estudam estratégias para a adoção de um sistema Que contribua para oportunizar a inclusão social dos jovens oriundos dessas escolas. Por outro lado, dados do IBGE ${ }^{(2,3)}$ já indicavam, no censo de 2000, o afunilamento progressivo da população de estudantes chegando ao ensino superior um percentual bastante reduzido de jovens.

Quanto à presença de pais ou irmãos com ensino superior os dados indicam que em ambas as instituições a maioria dos discentes não possuem, sendo na faculdade (A) $58 \%$ para os pais e $61,8 \%$ irmãos e na faculdade (B) 73,3\% para os pais e $58,3 \%$ irmãos. Estes achados reforçam os dados do IBGE ${ }^{(2,3)}$ em relação ao Quantitativo reduzido de pessoas com ensino superior em nossa população.

Em relação à presença de familiares Que trabalham na área de saúde foi verificado Que na instituição (A) $55 \%$ dos jovens têm e destes, 64,2\% são profissionais de enfermagem. Na instituição (B) $49,1 \%$ também possuem e destes $72,8 \%$ são trabalhadores de enfermagem. Estes dados indicam Que a presença de familiares trabalhadores na área de saúde e, especialmente na enfermagem, é um dos fatores Que contribuem para a inserção desses jovens na enfermagem.

A distribuição dos discentes Quanto aos meios de obtenção de informações a respeito da profissão demonstrou Que a maioria dos acadêmicos teve acesso a informação através de meios informais como parentes e amigos ((92(A) e 76(B)) e, também, pelos meios de comunicação formais como jornal, livro ou revista (49 (A) e 32(B)), conforme dados da tabela 1 . Estes achados revelam Que os jovens ao

Tabela 1. Distribuição dos discentes das instituições A e B conforme os meios de obtenção de informações acerca da profissão. Rio de Janeiro, 2004-2005.

\begin{tabular}{lcc}
\hline Meios de informação & Fi (A) & Fi (B) \\
\hline Jornal /ivro/ revista & 49 & 32 \\
Televisão & 02 & 11 \\
Amigos & 42 & 34 \\
Parentes & 50 & 42 \\
Palestras & 16 & 13 \\
Outros & 39 & 33 \\
Questão permite mais de uma resposta & - & - \\
\hline
\end{tabular}

Tabela 2. Distribuição dos discentes de acordo com os fatores Que motivaram a opção profissional. Rio de Janeiro, 2004-2005.

\begin{tabular}{lcc}
\hline Fatores & $\mathrm{Fi}(\mathrm{A})$ & $\mathrm{Fi}(\mathbf{B})$ \\
\hline Interesse/ afinidade pela área da saúde & 71 & 52 \\
Gostar de cuidar de pessoas & 63 & 43 \\
Mercado de trabalho promissor & 44 & 20 \\
Identificação com a profissão & 30 & 25 \\
Maior chance de ingresso no curso superior & 28 & 30 \\
Influência de parentes e amigos & 12 & 17 \\
\hline
\end{tabular}

Tabela 3. Distribuição dos discentes de acordo com a expectativa em relação à profissão. Rio de Janeiro, 20042005.

\begin{tabular}{lcc}
\hline Expectativa & $\mathrm{Fi}(\mathrm{A})$ & $\mathrm{Fi}(\mathrm{B})$ \\
\hline Realização profissional & 66 & 40 \\
Realização pessoal & 65 & 61 \\
Retorno financeiro & 48 & 56 \\
Poder ajudar o próximo & 44 & 30 \\
Aquisição de conhecimento teórico-prático & 30 & 40 \\
Reconhecimento e valorização da enfermagem & 19 & 25 \\
\hline
\end{tabular}


optarem por uma profissão buscam informações, preferencialmente, entre parentes e amigos. Os demais meios de comunicação foram relegados a segundo plano, de acordo com os achados.

Quanto aos fatores Que motivaram a escolha da enfermagem como opção profissional dos discentes está o interesse/afinidade pela área da saúde (7I(A) e 52(B)), gostar de cuidar de pessoas (63(A) e 43(B)) e o mercado de trabalho promissor (44(A) e 20(B)). conforme indica a tabela 2. Estes achados estão em consonância com a literatura ${ }^{(1,6,11,12)}$ evidenciando Que o aluno ingressante na enfermagem faz esta opção pelo seu interesse com a área de saúde e com o cuidar de pessoas. Todavia, o mercado de trabalho promissor tem sido apontado, demonstrando Que os alunos estão valorizando este aspecto ao escolherem uma profissão e que a enfermagem está sendo visualizada como uma carreira com retorno financeiro satisfatório. A maior chance de ingresso no curso superior, também, foi mencionada denotando a tendência do alunado em optar por carreiras conforme a possibilidade de aprovação no Vestibular.

Um aspecto a ser observado é Que embora tenham indicado a obtenção de informações acerca da profissão com parentes e amigos, os jovens não evidenciam Que este fator foi decisório para sua opção profissional.

Quanto à expectativa em relação à profissão os dados indicam Que os discentes esperam a realização profissional (66(A) e 40(B)), pessoal (65(A) e $6 \mathrm{I}(\mathrm{B})$ ) e o retorno financeiro (48(A) e 56(B)) com a carreira. A ajuda ao próximo e aQuisição de conhecimentos também está presente evidenciando a preocupação dos jovens com o aspecto humanitário e a formação do profissional. Vale acrescentar, todavia, Que os alunos da instituição (B) em sua maioria estão inseridos no mercado de trabalho como profissionais de saúde e vislumbram a realização pessoal, além do retorno financeiro com a nova carreira, como se observa na tabela 3.

\section{CONCLUSÕES}

O estudo evidenciou Que nas duas instituições de ensino o conjunto amostral é composto, em sua maioria, por adultos jovens, do sexo feminino, solteiras, sem filhos, pertencentes às classes $B$ e $C$ Que buscam a enfermagem por sua afinidade/inserção na área de saúde, considerando Que a maioria dos alunos que exercem atividade remunerada na instituição privada é profissional de enfermagem.

O mercado de trabalho em expansão e a oportunidade de uma remuneração melhor são fatores Que atraem o aluno da faculdade particular para a graduação em enfermagem. A profissão e o campo de atuação do enfermeiro são desconhecidos pela maioria dos alunos da faculdade pública Que associam a imagem do profissional à pessoa Que ajuda ao próximo numa visão de solicitude e assistencialismo.

A presença de familiares Que atuem na área da saúde é um dos fatores Que contribuem para a inserção do aluno na graduação em enfermagem se considerar Que obtiveram informações acerca da profissão, principalmente, junto a amigos e familiares. Todavia, ao indicar os fatores Que motivaram a escolha da profissão este aspecto não foi o mais incidente, havendo prevalência da afinidade com a área da saúde e o gostar de cuidar de pessoas, salientado em outros estudos $^{(1,6,10-12)}$.

A divulgação da profissão junto à sociedade e, especialmente, entre os alunos Que buscam uma opção profissional torna-se relevante, considerando a desinformação daQueles Que ingressam na graduação em enfermagem ${ }^{(6)}$. Ações voltadas para a orientação dos alunos de ensino médio, muitos ainda indefinidos em relação a uma carreira, seriam oportunas e poderiam esclarecer o alunado sobre a enfermagem e o mercado de trabalho, despertando o interesse para a profissão.

\section{REFERÊNCIAS}

I. Menezes SS, Baptista SS, Barreira IA. O perfil das(os) alunas(os) de enfermagem da Escola de Enfermagem Anna Nery: décadas de 20,30 e 90. Esc Anna Nery Rev Enferm 1998;2(1/2):3447.

2. Instituto Brasileiro de Geografia e Estatística. Síntese de indicadores sociais. [citado 15 mai 2005]. Disponível em: URL: http://www.ibge.gov.br

3. Instituto Brasileiro de Geografia e Estatística. Síntese de indicadores sociais - Pesquisa Nacional por Amostra de Domicílios 2003. [citado 15 mai 2005]. Disponível em: URL: http://www.ibge.gov.br

4. Instituto Brasileiro de Geografia e Estatística. Síntese de indicadores sociais - Trabalho e educação. [citado 15 mai 2005]. Disponível em: http:// www.ibge.gov.br

5. Conselho Federal de Enfermagem. Estatística. [citado 19 mai 2005]. Disponível em: URL: http://www.portalcofen.com.br

6. Spíndola T, Moreira A. O aluno e a enfermagem: por Que esta opção profissional? Esc Anna Nery Rev Enferm 1999; 3(3): 25-36.

7. Universidade Federal do Rio de Janeiro (UFRI). Vestibular. [citado 29 abr 2005]. Disponível em: URL: http:// www.vestibular.ufrj.br.
8. Universidade Federal Fluminense (UFF). Vestibular. [citado 28 abr 2005]. Disponível em: URL: http://www.coseac.uff.br/Nest 2005/index.htm.

9. Universidade do Estado do Rio de Janeiro (UERI). Vestibular. [citado 29 abr 2005]. Disponível em: URL: http:// www.vestibular.uerj.br.

10. Rodrigues ARR, Scatena MCM, Labate RC. O aluno ingressante na enfermagem - abordagem compreensiva. Rev Enferm UERJ 1997; 5(1): 331-9.

11. Acuri EAM, Araújo TL, Oliveira MAC. Fatores Que influenciaram alunos ingressantes na Escola de Enfermagem da USP, em 1981, na escolha da enfermagem como opção profissional. Rev Esc Enferm USP 1983; 17(1): 5-19.

12. Santos CE, Leite MMJ. O perfil do aluno ingressante em uma universidade particular da cidade de São Paulo. Rev Bras Enferm 2006; 59(2): 154-6.

13. Vargens OMC. Tentando descobrir um modo de fazer enfermagem sem ser enfermeiro: os conflitos do estudante na construção da imagem da profissão. Rio de Janeiro (RJ): Edição do Autor; 1997.

14. Silva MTN. Sobre enfermagem - enfermeira: o imaginário dos familiares das alunas ingressantes no curso de graduação. 
Enfermagem como opção: perfil de graduandos de duas instituições de ensino

[tese]. Rio de Janeiro (RI): Escola de Enfermagem Anna Nery, Universidade Federal do Rio de Janeiro; 2000.

15. Trivinos ANS. Introdução à pesquisa em Ciências Sociais - a pesQuisa Qualitativa em educação. $3^{\text {a }}$ ed. São Paulo (SP): Atlas; 1994.

16. Polit DF, Hungler BP. Fundamentos de pesquisa em enfermagem. $3^{\mathrm{a}}$ ed. Porto Alegre (RS): Artes Médicas; 1995.

17. Gauthier JHM, Cabral IE, Santos I, Tavares CMM. Pesquisa em enfermagem novas metodologias aplicadas. Rio de Janeiro
(RJ): Guanabara/Koogan; 1998.

18. Ministério da Saúde (BR). Conselho Nacional de Saúde. Diretrizes e normas regulamentadoras de pesquisas envolvendo seres humanos. Resolução no 196/96. Brasília (DF): MS/FIOCRUZ; 1996.

19. Fonseca IS, Martins GA. Curso de estatística. $6^{\mathrm{a}}$ ed. São Paulo (SP): Atlas; 1996.

20. Vieira S. Elementos de estatística. $4^{a}$ ed. São Paulo (SP): Atlas; 2003. 